ORIGINAL ARTICLE

\title{
Association of serum uric acid with systemic blood pressure - A Cross Sectional study.
}

Shumail Saeed Siddiqui ${ }^{1}$, Shagufta Memon ${ }^{2}$, Shumaila Shaikh ${ }^{3}$, Umair Ali Soomro ${ }^{4}$, Sadia Tabassum ${ }^{5}$, Kashif Rasheed Shaikh ${ }^{6}$, Haji Khan Khoharo ${ }^{7}$

Article Citation: Siddiqui SS, Memon S, Shaikh S, Soomro UA, Tabassum S, Shaikh KR, Khoharo HK. Association of serum uric acid with systemic blood pressure - A Cross Sectional study. Professional Med J 2022; 29(1):88-93. https://doi.org/10.29309/TPMJ/2022.29.01.4747

ABSTRACT... Objective: To determine association of Serum Uric Acid levels (SUA) in subjects suffering Systemic Blood Pressure and to determine its association with systolic and diastolic blood pressure. Study Design: Cross Sectional Study. Setting: Department of Faculty of Medicine and Allied Medical Sciences, Isra University, Hyderabad, Sindh, Pakistan. Period: January 2018 to September 2019. Material \& Methods: 150 diagnosed cases of systemic hypertension and 150 controls were selected though non-probability purposive sampling according to inclusion and exclusion criteria. 2 ml venous blood was taken, centrifuged and sera were used for uric acid. Data was saved in a pre- structured Performa. Statistical software (SPSS v 21.0, IBM, Incorporation, USA) of data variables was analyzed at $95 \% \mathrm{Cl}(\mathrm{P} \leq 0.05)$. Results: Serum uric acid in controls was $2.93 \pm 0.72$ compared to cases $4.25 \pm 1.44 \mathrm{mg} / \mathrm{dl}(\mathrm{P}=0.0001)$. Hyperuricemia was observed in $58(38.6 \%)$ cases compared to 23 (15.3\%) controls. Uric acid shows strong positive association with Systolic BP $\left(r=0.52^{*}, p=0.0001\right)$ and Diastolic BP $\left(r=0.46^{* *}, p=0.0001\right)$. Conclusion: We found hyperuricemia in $58(38.6 \%)$ of systemic hypertension cases. Systolic and Diastolic Blood pressure show positive association with uric acid.

Key words: $\quad$ Age, Body Weight, Diastolic BP, Systolic BP, Uric Acid.

\section{INTRODUCTION}

Uric acid circulates in the blood plasma that is generated by the normal turnover of nucleic acids. Cellular pool of nucleic acids is a rich source of de- novo synthesis of uric acid. Serum uric acid (SUA) is present as mono-sodium urate (MSU). ${ }^{1,2}$ Probable association of SUA has been considered since a century. During the $20^{\text {th }}$ century, linkage of serum uric acid and systemic blood pressure has waxed and waned because of lack of evident research. ${ }^{2,3}$ It was first time reported by a previous rat model study ${ }^{4}$ that was induced hyperuricemia with oxonic acid - an uricase inhibitor, and noticed a decrease in SUA with a uricosuric drug. Elevated serum uric acid is termed as hyperuricemia and has become a hot research topic of recent years. However, the association of SUA and high systemic blood pressure has not been unanimously accepted except the above quoted rat model experiment. Few of randomized trials failed to find this relationship. ${ }^{5,6}$ Palmer et $\mathrm{al}^{6}$ suggested that the BMI (body mass index) may be a potential confounding factor in the development of uric acid related metabolic disorders. While other studies ${ }^{1,5}$ could not find deleterious effect of SUA against the endothelial function that is a potential mechanisms for the systemic hypertension.

Systemic blood pressure has become a serious health problem in the developing countries due to high meat intake. One billion people and 7.1 million deaths have been taken by the high systemic blood pressure. Recently, serum uric acid has been has been reported linked with the systemic hypertension. Previous studies ${ }^{5-7}$ reported positive correlation of hypertension and systemic hypertension. Uric acid has been linked
1. MBBS, M.Phil, Assistant Professor Pathology, Indus Medical College, Tando Muhammad Khan, Sindh, Pakistan.

2. MBBS, M.Phil, Assistant Professor Physiology, Khairpur Medical College, Khairpur Mirs, Sindh, Pakistan.

3. MBBS, M.Phil, Assistant Professor Biochemistry, Khairpur Medical College, Khairpur Mirs, Sindh, Pakistan.

4. MBBS, M.Phil, Assistant Professor Hematology, Indus Medical College, Tando Muhammad Khan, Sindh, Pakistan.

5. MBBS, M.Phil, Assistant Professor Biochemistry, Suleman Roshan Medical College, Tando Adam, Sindh, Pakistan.

6. MBBS, M.Phil, Associate Professor Pharmacology, Suleman Roshan Medical College, Tando Adam, Sindh, Pakistan.

7. MBBS, M.Phil, FCPS, Associate Professor Faculty of Medicine, and Allied Medical Sciences, Isra University, Hyderabad, Sindh, Pakistan.

\author{
Correspondence Address: \\ Dr. Kashif Rasheed Shaikh \\ Department of Pharmacology \\ Suleman Roshan Medical College, \\ Tando Adam, Sindh, Pakistan. \\ mailboxKxm@gmail.com
}

Article received on:

Accepted for publication:

$28 / 04 / 2020$ $16 / 11 / 2020$ 
to the microalbuminuria in systemic hypertension. Few studies reported hyperuricemia is a risk factor for the systemic hypertension. Previous studies ${ }^{5,6}$ reported 25 - 50\% frequency of hyperuricemia in systemic hypertension. Hyperuricemia is now established risk factor for the hyperlipidemia, dyslipidemia, insulin resistance, kidney disease and systemic hypertension. Some studies have reported association of hyperuricemia with systemic hypertension in women ${ }^{7-9}$, few in men ${ }^{10}$ and others have reported this association in both genders. ${ }^{11} \mathrm{~A}$ previous study ${ }^{12}$ reported significant association of hyperuricemia and systemic hypertension in less than 40 years of age. While other studies ${ }^{13,14}$ demonstrated contrasting occurrence in older than 40 years.

The controversial reports compelled the researchers to investigate further research in indigenous population. The present prospective study was conducted to analyze serum uric acid levels (SUA) in subjects suffering high Systemic BP and to determine its association with systolic and diastolic blood pressure.

\section{MATERIAL \& METHODS}

The present cross sectional study was conducted at the Faculty of Medicine and Allied Medical Sciences, Isra University, Hyderabad, Sindh, Pakistan from January 2018 to September 2019. Study was conducted after ethical approval of the institute (IU: 2019/1200/BM). 150 diagnosed cases of systemic hypertension and 150 controls were selected though non-probability purposive sampling according to inclusion and exclusion criteria. Sample size was calculated by "Rao - software for sample size calculation. Both inpatient and outpatient department patients were included in the study protocol. Diagnosed cases of systemic hypertension, age 40 - 60 years, both gender qualified for inclusion in the study protocol. Patients taking thiazide diuretics, diabetes mellitus, hyperthyroidism, endocrine disorders, kidney disease, alcoholics and Ischemic heart disease were excluded. Volunteers are interviewed, history was taken in detail, and physical examination was performed to exclude any systemic disorder. Volunteers were asked for blood sampling. A pre structured proforma was designed for data entry.

Hypertension was defined as per JNC- VII criteria. Blood pressure was measured with a mercury sphygmomanometer. 5 minutes rest in sitting position was allowed for blood pressure reading. 3 readings of systolic and diastolic BP were taken in sitting position. Electric weight machine weighed the subjects. Body mass index (BMI) was estimated by formula; body weight (Kg)/ height $\left(\mathrm{m}^{2}\right)=$ BMI. $2 \mathrm{ml}$ venous blood was taken from a prominent vein after tourniquet ligature preferably form ante - cubital fossa. Blood was centrifuged (x3000 rpm for 12 minutes) and sera were used for detection of uric acid by colorimetric method. Serum creatinine was estimated by Jaffe's method. And BUN was measured from blood urea. Sera were stored at $-20^{\circ} \mathrm{C}$ for later use. Computer based statistical software (SPSS v 21.0, IBM, Incorporation, USA) analyzed the data variables. Continuous variables difference was analyzed by Student's t test and Chi $\left(\mathrm{x}^{2}\right)$ square calculated the categorical variables. Bivariate method (Pearson's correlation) was run on SPSS -21.0 for association of serum uric acid with the research variables. Data variables were analyzed at $95 \% \mathrm{Cl}(\mathrm{P} \leq 0.05)$.

\section{RESULTS}

Age of controls and cases was $49.24 \pm 7.83$ and $48.47 \pm 6.25$ years respectively $(P=0.071)$ (Table-I). Controls subjects included; 121 (80.6\%) male and 29 (19.3\%) were female while cases included 119 (79.9\%) male and 31 (20.6\%) female $(P=0.083)$ (Table-II). Body weight and BMl $77.7 \pm 12.35$ vs. $79.27 \pm 13.87 \mathrm{Kg}(P=0.30)$ and $27.53 \pm 3.3$ and $28.4 \pm 3.6 \mathrm{~kg} / \mathrm{m}^{2}$ in control and cases respectively $(P=0.0001)$. Systolic and Diastolic BP, Uric acid, BUN and S. creatinine are shown in Table-I. Serum uric acid in controls was $2.93 \pm 0.72$ compared to cases $4.25 \pm 1.44 \mathrm{mg} / \mathrm{dl}$ $(\mathrm{P}=0.0001)$. Hyperuricemia was observed in 58 (38.6\%) cases compared to $23(15.3 \%)$ controls $\left(X^{2}=21.7, P=0.0001\right)$ (Table-IV). Association of Pearson's correlation analysis is shown in table-V. Uric acid shows strong positive association with Systolic BP $\left(r=0.52^{*}, p=0.0001\right)$ and Diastolic BP $\left(r=0.46^{\star *}, p=0.0001\right)$. Uric acid association with age and body weight was non - significant. 


\begin{tabular}{|l|c|c|c|}
\hline & $\begin{array}{c}\text { Control } \\
(\mathbf{n = 1 5 0 )}\end{array}$ & $\begin{array}{c}\text { Cases } \\
(\mathbf{n = 1 5 0 )}\end{array}$ & $\begin{array}{c}\text { P- } \\
\text { Value }\end{array}$ \\
\hline Age (years) & $49.24 \pm 7.83$ & $48.47 \pm 6.25$ & 0.071 \\
\hline $\begin{array}{l}\text { Body weight } \\
(\mathrm{kg})\end{array}$ & $77.7 \pm 12.35$ & $79.27 \pm 13.87$ & 0.30 \\
\hline BMI (kg/m²) & $27.53 \pm 3.30$ & $28.48 \pm 3.61$ & 0.0001 \\
\hline $\begin{array}{l}\text { Systolic BP } \\
\text { (mmHg) }\end{array}$ & $148.3 \pm 22.46$ & $130.86 \pm 8.57$ & 0.0001 \\
\hline $\begin{array}{l}\text { Diastolic BP } \\
\text { (mmHg) }\end{array}$ & $83.20 \pm 15.10$ & $70.77 \pm 8.55$ & 0.0001 \\
\hline $\begin{array}{l}\text { Uric acid } \\
\text { (mg/dl) }\end{array}$ & $2.93 \pm 0.72$ & $4.25 \pm 1.44$ & 0.0001 \\
\hline BUN (mg/dl) & $3.91 \pm 0.15$ & $4.30 \pm 1.06$ & 0.0001 \\
\hline $\begin{array}{l}\text { S. Creatinine } \\
\text { (mg/dl) }\end{array}$ & $1.41 \pm 0.25$ & $1.70 \pm 0.95$ & 0.0001 \\
\hline \multicolumn{1}{|c|}{ Table-I. Findings of control and cases. } \\
\hline
\end{tabular}

Table-II. Gender distribution in control and cases.

\begin{tabular}{|l|c|c|c|c|c|}
\hline & \multicolumn{2}{|c|}{$\begin{array}{c}\text { Control } \\
(\mathbf{n = 1 5 0 )}\end{array}$} & \multicolumn{2}{c|}{$\begin{array}{c}\text { Cases } \\
(\mathbf{n = 1 5 0 )}\end{array}$} & $\begin{array}{c}\text { P. } \\
\text { Value }\end{array}$ \\
\hline & Male & Female & Male & Female & \\
\hline Normouricemia & 71 & 21 & 103 & 24 & \multirow{2}{*}{0.0001} \\
\hline Hyperuricemia & 50 & 8 & 16 & 7 & \\
\hline Total & 121 & 29 & 119 & 31 & \\
\hline
\end{tabular}

Table-III. Serum Uric acid levels in control and cases.

\begin{tabular}{|l|c|c|c|}
\hline & $\begin{array}{c}\text { Control } \\
(\mathbf{n = 1 5 0 )}\end{array}$ & $\begin{array}{c}\text { Cases } \\
(\mathbf{n = 1 5 0 )}\end{array}$ & \multirow{2}{*}{ P-Value } \\
\hline Normouricemia & $127(84.6 \%)$ & $92(61.3 \%)$ & \\
\cline { 1 - 3 } Hyperuricemia & $23(15.3 \%)$ & $58(38.6 \%)$ & \multirow{2}{*}{0.0001} \\
\cline { 1 - 3 } Total & 150 & 150 & \\
\cline { 1 - 3 } & & &
\end{tabular}

Table-IV. Serum Uric acid in control and cases.

\begin{tabular}{|l|c|c|}
\hline & R-Value & P-Value \\
\hline Age (years) & $0.09^{\star}$ & 0.09 \\
\hline Body weight $(\mathrm{kg})$ & $0.025^{\star}$ & 0.67 \\
\hline Systolic BP $(\mathrm{mmHg})$ & $0.52^{\star}$ & 0.001 \\
\hline Diastolic BP $(\mathrm{mmHg})$ & $0.46^{\star}$ & 0.001 \\
\hline
\end{tabular}

Table-V. Pearson's correlations of Uric acid. ** Correlation is significant at the 0.01 level (2-tailed)

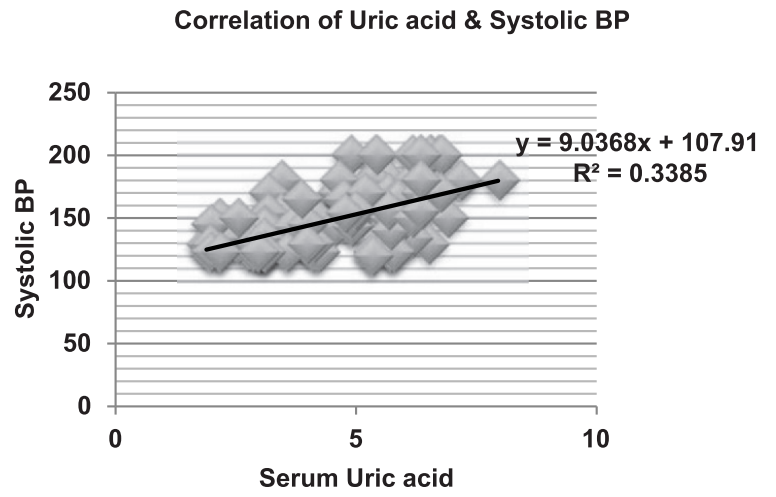

Figure-1. Scatter plot shows positive correlation of Systolic BP and Uric acid. ( $r=0.52, P=0.0001)$.

Correlation of Uric acid \& Diastolic BP

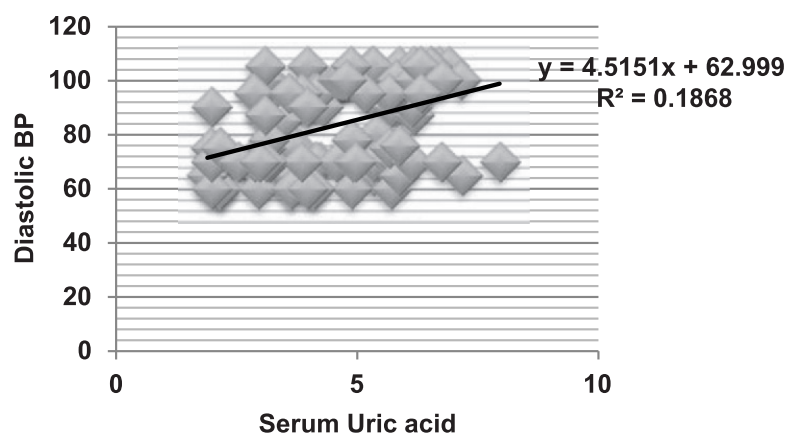

Figure-2. Scatter plot shows positive correlation of Diastolic BP and Uric acid. $(r=0.46, p=0.0001)$

\section{DISCUSSION}

The present cross sectional study was conducted at the tertiary care hospital. The study analyzed the serum uric acid levels in systemic hypertension and its association with the systolic and diastolic BP. Uric acid samples of systemic hypertension cases were compared with control (non hypertensive) and results were calculated on Statistical software. Age, body weight and BMI of cases and controls were matched to exclude any research bias. The age of cases and controls was $49.24 \pm 7.83$ and $48.47 \pm 6.25$ years respectively $(\mathrm{P}=0.071)$ (Table-l).

Cases and controls belonged to $4^{\text {th }}-6^{\text {th }}$ decade of life. Age finding of present study sample are consistent with the previous studies ${ }^{15,16}$ as they reported 40- 60 years age was commonest. This particular group was selected because the systemic hypertension is common in this age..$^{12,17-}$ 
${ }^{19} \mathrm{~A}$ previous study ${ }^{12}$ observed similar age in their study. However, a previous study ${ }^{17}$ from Pakistan reported young age of 20 years being the majority of cases in their study that is controversial to present and previous studies. ${ }^{12,17-19}$ In present study, the controls subjects included; 121 (80.6\%) male and $29(19.3 \%)$ were female while cases included 119 (79.9\%) male and 31 (20.6\%) female $(P=0.083)$. Body weight and BMI $77.7 \pm 12.35$ vs. $79.27 \pm 13.87 \mathrm{Kg}(P=0.30)$ and $27.53 \pm 3.3$ and $28.4 \pm 3.6 \mathrm{~kg} / \mathrm{m}^{2}$ in control and cases respectively $(\mathrm{P}=0.0001)$. We observed hyperuricemia in 58 (38.6\%) cases compared to $23(15.3 \%)$ controls $\left(X^{2}=21.7, P=0.0001\right)$ (table 4). This finding of hyperuricemia is in line with previous studies. ${ }^{5,6}$ Serum uric acid in controls was $2.93 \pm 0.72$ compared to cases $4.25 \pm 1.44 \mathrm{mg} / \mathrm{dl}$ that revealed statistically significant difference $(P=0.0001)$. The finding is consistent with previous studies. ${ }^{12,13}$ But a previous study ${ }^{17}$ observed high uric acid levels of $6.18 \pm 1.79 \mathrm{mg} / \mathrm{dl}$ in cases compared to $5.60 \pm 1.83 \mathrm{mg} / \mathrm{dl}$ in controls. The finding of above study is inconsistent to present and previous studies. ${ }^{12,13}$ Controversial results are probably because of living patterns, life style, and in major the dietary habits. We think high uric acid levels of above study ${ }^{17}$ are because of high meat intake that is not mentioned properly. In present study, the uric acid in controls was $2.93 \pm 0.72$ compared to cases $4.25 \pm 1.44 \mathrm{mg} / \mathrm{dl}(\mathrm{P}=0.0001)$. Another previous study ${ }^{17}$ reported similar findings of high uric acid levels in those suffering from prehypertension and hypertension.

They observed uric acid levels of $5.89 \pm 0.97$ $\mathrm{mg} / \mathrm{dl}$ in pre-hypertension $\mathrm{mg} / \mathrm{dl}, 6.56 \pm 0.64$ $\mathrm{mg} / \mathrm{dl}$ in hypertension and $4.91 \pm 0.88 \mathrm{mg} / \mathrm{dl}$ in control. Similar observation of high serum uric acid levels in systemic hypertension patients has been reported in another study. ${ }^{20}$ Serum uric acid in systemic hypertension patients in present study was noted as $4.25 \pm 1.44 \mathrm{mg} / \mathrm{dl}$ that is in agreement with previous studies ${ }^{20,21}$ that found $5.8 \mathrm{mg} / \mathrm{dl}$ in hypertensive patients $(P<0.05)$. The present study analyzed the association of serum uric acid with systolic and diastolic BP and found strong positive correlation between them. Our finding of association of Pearson's correlation is shown in table 5. Uric acid shows strong positive association with Systolic BP $\left(r=0.52^{*}, p=0.0001\right)$ and Diastolic BP $\left(r=0.46^{* *}, p=0.0001\right)$. Uric acid association with age and body weight was non - significant $(P>0.05)$. This is in accordance to previous study by Vakil et $\mathrm{al}^{21}$ that observed positive correlation of uric acid with systolic and diastolic blood pressure. The findings of high uric acid in systemic hypertension are supported by other previous studies. ${ }^{22-25}$ The present study findings supported by previous study, suggests cause effect association of uric acid and systemic hypertension.

Limitation of present study is a small sample size belonged of particular ethnicity hence findings may not be generalized for other geographical populations. We cannot ascertain the causeeffect relationship of serum uric acid and systemic hypertension because of cross sectional study design. We conclude that the patients of systemic hypertension must be screened for the serum uric acid levels for better patient outcome along with anti-hypertensive drugs and if needed uricosuric drugs may be prescribed, but this needs further studies at national level.

\section{CONCLUSION}

We found hyperuricemia in 58 (38.6\%) of systemic hypertension cases. Systolic and Diastolic Blood pressure shows positive association with uric acid. Prospective studies with large sample size are recommended to establish the cause-effect relationship. Systemic hypertension patients should be screened for uric acid and appropriate therapy.

\section{Copyright $\subseteq 16$ Nov, 2020.}

\section{REFERENCES}

1. Rock KL, Kataoka H, Lai JJ. Uric acid as a danger signal in gout and its comorbidities. Nature Rev Rheumato 2013; 9 (1): 13-23.

2. Mule G, Nardi E, Lattuca L, Cottone S. Hyperuricemia and high blood pressure at rest and during exercise: Guilty or innocent? The jury is still out. J Clin Hypertension 2018; 20 (3): 557-559.

3. Feig DI. Hyperuricemia and hypertension. Adv Chronic Kid Dis 2012; 19 (6): 377-385. 
4. Mazzali M, Hughes J, Kim YG. Elevated uric acid increases blood pressure in the rat by a novel crystal independent mechanism. Hypertension 2001; 38 (5):1101-6.

5. Qabulio SN, Shahnawaz S, Mansoor K, Jadoon A, Akhter $S$, Tanwir F. Increased serum uric acid association with hypertension. Emerg Med Inves 2017: EMIG-143.

6. Palmer TM, Nordestgaard BG, Benn M. Association of plasma uric acid with ischaemic heart disease and blood pressure: Mendelian randomisation analysis of two large cohorts. British Med J 2013; 34718(1): f4262.

7. Grayson PC, KimSY, LaValley M, ChoiHK. Hyperuricemia and incident hypertension: $A$ systematic review and meta-analysis. Arthr Care Res 2011; 63 (1): 102-110.

8. Kuwabara M, Hisatome I, Niwa K. Uric acid is a strong risk marker for developing hypertension from prehypertension a 5-year Japanese cohort study. Hypertension 2018; 71(1): 78-86.

9. Nishio S, Maruyama Y, Sugano N, Hosoya T, Yokoo T, Kuriyama $S$. Gender interaction of uric acid in the development of hypertension. Clin Exp Hypert 2017; 40 (5): 446-451.

10. Loeffler LF, Navas-Acien A, Brady TM, Miller III ER, Fadrowski JJ. Uric acid level and elevated blood pressure in US adolescents: National Health and Nutrition Examination Survey, 1999-2006. Hypertension 2012; 59 (4):811-817.

11. Shrivastava C, Sharma S, Suhalka ML, Kaur M. Hyperuricaemia and essential hypertension: A case control study in Southern Rajasthan. Int J Res Med Sci 2016; 4:78-83.

12. Lee JJ, Ahn J, Hwang J. Relationship between uric acid and blood pressure in different age groups. Clin Hypert 2015; 21:14.

13. Yokoi Y, Kondo T, Okumura N. Serum uric acid as a predictor of future hypertension: Stratified analysis based on body mass index and age. Prev Med 2016; 90: 201-206.

14. Cheng W, Wen S, Wang Y. The association between serum uric acid and blood pressure in different age groups in a healthy Chinese cohort. Medicine (Baltimore) 2017; 96 (50): Article e8953.
15. Ansari RN, Gandhi RV, Saiyed MN, Jain KD. Study of prevalence and impact of hyperuricemia in a patient of hypertension. Int J Adv Med 2017; 4:367-9.

16. Ali N, Perveen R, Rahman S, Mahmood S, Rahman $S$, Islam S. Prevalence of hyperuricemia and the relationship between serum uric acid and obesity: $A$ study on Bangladeshi adults. PLOS ONE 2018; 13(11): e0206850:1-12.

17. Habib MS, Khatoon S, Sand AA. Hyperuricemia; a risk factor for development of hypertension in Pakistani community. Professional Med J 2018; 25(3):381-386.

18. Kumar M, Kumari S. A study to analyse the potentiality of serum uric acid to use as a biomarker to detect essential hypertension severity. J Med Sci Clin Res2019; 07 (07):962-66.

19. Lin X, Wang X, Li X, Song L, Meng Z, Yang Q, et al. Gender and age specific difference in the association of hyperuricemia and hypertension; A cross sectional study. Int`I J Endocrinol 2019; Article ID 7545137:1 - 9.

20. Lan $Q$, Wu $H$, Zhou X, Zheng L, Lin F, Meng Q, et al. Predictive value of uric acid regarding cardiometabolic disease in a community-dwelling older population in Shanghai: A Cohort Study. Front Med 2020; 7(24): 1- 8 .

21. Vakil A, Vrkariya P, Barafiwala V, Gamit K, Patel D, Doctor N. Study of serum uric acid level in hypertension. IOSR J Dent Med Sci 2017; 16: 69-73.

22. Park B, Lee HA, Lee SH, Park BM, Park EA, Kim HS, et al. Association between serum levels of uric acid and blood pressure tracking in childhood. Am J Hypertension 2017; 30(7): 713-18.

23. Mukhopadhyay P, Ghosh S, Pandit K, Chatterjee P, Majhi $\mathrm{B}$, Chowdhury S. Uric acid and its correlation with various metabolic parameters: A population- based study. Indian J Endocr Metab 2019; 23:134-9.

24. McMullan CJ, Borgi Lea Fisher N, Curhan G, Forman $\mathrm{J}$. Effect of uric acid lowering on renin-angiotensinsystem activation and ambulatory BP: A randomized controlled trial. Clin J Am Soc Nephrol 2017; 12: 807816.

25. Castro-Torres Y, Khan NY, Carmona-Puerta RC. Levels of uric acid and increased diastolic blood pressure: Risk factors for atrial fibrillation in patients older than 60 years. Rev Assoc Med Bras 2017; 63(7):600-5. 


\section{AUTHORSHIP AND CONTRIBUTION DECLARATION}

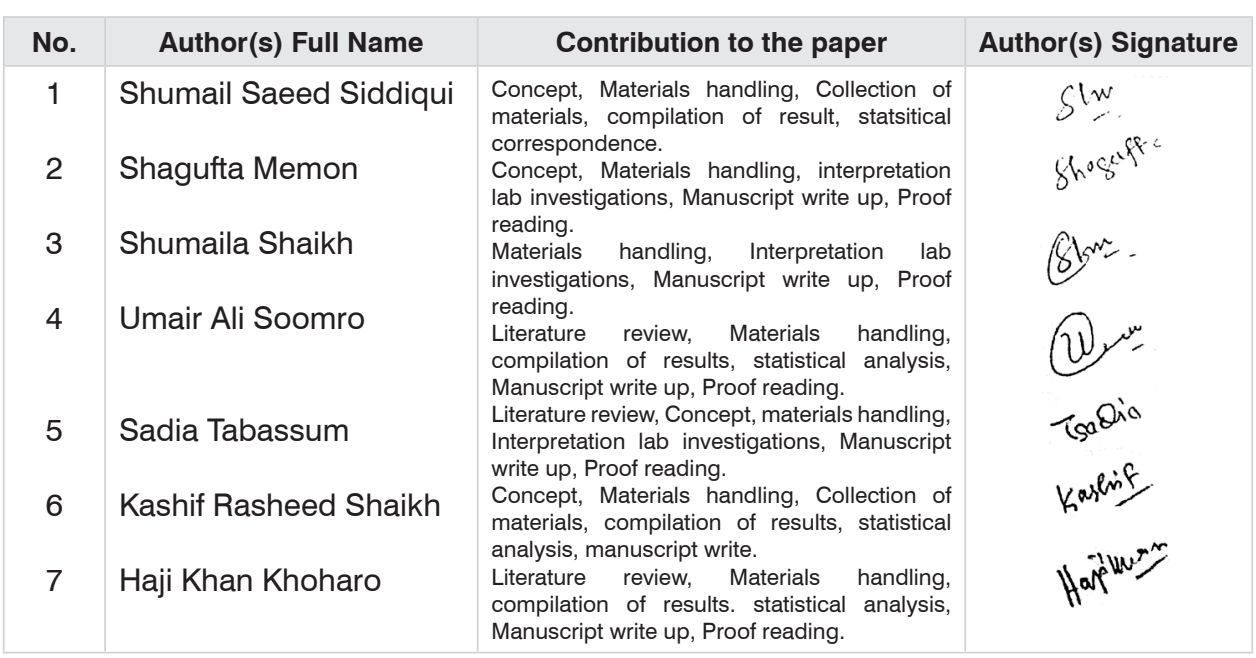

